\title{
Benefits and challenges of practicing taekwondo to adolescents in Addis Ababa City, Ethiopia
}

\author{
Michael Emru TADESSE* \\ Mizan-Tepi University (Ethiopia) \\ Recepción: 30/12/2015; Aceptación: 20/03/2016; Publicación: 26/03/2016.
}

\begin{abstract}
This study aimed at examining the benefits and challenges of practicing Taekwondo (TKD) to adolescents in Addis Ababa. In so doing, the study investigated the nature of TKD training, benefits of practicing TKD, and challenges/problems related with practicing TKD. A descriptive concurrent mixed methods research design was used. Accordingly, the quantitative part of the study had 108 TKD adolescent participants while the qualitative part had 12 participants (eight TKD adolescents and four TKD coaches), from four TKD clubs in Addis Ababa. Both one-stage cluster sampling technique and purposive sampling technique were employed to select participants for the quantitative and qualitative parts of the study, respectively. Questionnaires and in-depth interviews were used to collect data from participants. Results of the study indicated: (1) the TKD training provided by the four TKD clubs was more of a modern/sport form of TKD; (2) TKD adolescents and coaches perceived that the benefits of TKD for adolescents are multifaceted, i.e., social benefits, physical benefits, mental benefits, self-defense, addiction avoidance, and other benefits; and (3) though majority (63.6\%) of the respondents claimed that they did not face any problem as a result of practicing TKD, the following were identified as major problems that could threaten the wellbeing of TKD adolescents: family-related problems, community-related problems, and competition-related problems. In general, results show that the training of TKD can have a multifaceted positive contribution to adolescents' wellbeing.
\end{abstract}

Keywords: Adolescent; combat sports; martial arts; taekwondo; wellbeing.

\section{Beneficios y desafíos en la práctica de taekwondo por adolescentes en Adís Abeba, Etiopía \\ Resumen}

El objetivo de este estudio fue analizar los beneficios y desafíos de la práctica de taekwondo (TKD) por adolescentes en Adís Abeba. Se investigó la naturaleza del entrenamiento de taekwondo, beneficios y desafíos/problemas relacionados con su práctica. Se utilizó un diseño de investigación con métodos mixtos, concurrentes y descriptivos. La parte cuantitativa del estudio contó con 108 practicantes de TKD adolescentes, y 12 en la parte cualitativa (ocho adolescentes y cuatro entrenadores de TKD), de cuatro clubes de TKD de Adís Abeba. Se emplearon técnicas de muestreo por conglomerados en una sola etapa y técnicas de muestreo intencional para seleccionar, respectivamente, a los participantes de las partes cuantitativas y cualitativas del estudio, utilizando cuestionarios y entrevistas en profundidad para la recogida de datos. Los resultados del estudio indicaron que: (1) el entrenamiento de TKD realizado en los cuatro clubes estudiados respondía a una forma moderna / deportivizada de TKD; (2) los adolescentes y entrenadores de TKD percibían que los beneficios del TKD para los adolescentes son multifacéticos, i.e., beneficios sociales, físicos, mentales, defensa personal, evitar adicciones y otros beneficios; y (3) aunque la mayoría $(63,6 \%)$ de los encuestados afirmó que no se enfrentaba a ningún problema como resultado de la práctica de TKD, se identificaron los siguientes como aquellos que podrían

\section{Benefícios e desafios da prática do taekwondo nos adolescentes, em Adis Abeba, Etiópia \\ Resumo}

O objetivo deste estudo foi o de analisar os benefícios e os desafios da prática de Taekwondo (TKD) em adolescentes, em Adis Abeba. Investigou-se a natureza do treino no taekwondo, dos benefícios e dos desafios/problemas relacionados com a prática. Recorreu-se a uma investigação com métodos mistos, concorrentes e descritivos. A parte quantitativa do estudo contou com 108 praticantes de TDK adolescentes e 12 na parte qualitativa (oito adolescentes e quatro treinadores de TDK), de quatro clubes de TDK, em Adis Abeba. Empregaram-se técnicas de amostragem por clusters e técnicas de amostragem intencional para selecionar, respectivamente, os participantes das partes quantitativas e qualitativas do estudo, utilizando questionários e entrevistas em profundidade para a recolha de dados. Os resultados do estudo indicam que: (1) o treino de TDK, realizado nos quatro clubes estudados, respondiam a uma forma moderna/desportiva de TDK; (2) os benefícios nos adolescentes são multifacetados (benefícios sociais, físicos, mentais, defesa pessoal, evita dependências e outros benefícios); (3) ainda que a maioria (63,6\%) dos entrevistados afirmasse que não se enfrentava nenhum problema como resultado da prática de TDK, identificaram-se os alguns que poderiam colocar em perigo o bem-estar dos adolescentes: problemas

\footnotetext{
* E-mail: michael.emru7@gmail.com. Address: Department of Social Work. Mizan-Tepi University. Mizan Campus (Ethiopia). Tel: +251-912285077.
} 
poner en peligro el bienestar de los adolescentes: problemas relacionados con el ámbito familiar, con el ámbito comunitario y con la competición. En general, los resultados muestran que el entrenamiento en TKD puede contribuir de un modo positivo y multifacético al bienestar de los adolescentes.

Palabras clave: Adolescentes; deportes de combate; artes marciales; taekwondo; bienestar. relacionados com o âmbito familiar, com o âmbito comunitário e com a competição. Em geral, os resultados mostram que o treino em TDK pode contribuir de um modo positivo e multifacetado com o bem-estar dos adolescentes.

Palavras-chave: Adolescentes; desportos de combate; artes marciais; taekwondo; bem-estar.

\section{Introduction}

Martial arts are basically conceptualized as methods of combat and/or self-defense which involve and combine, among others, physical aspects of combat, strategy, philosophy, and tradition (Green, 2001). Nowadays, martial arts have become universally practiced form of sport (Vertonghen \& Theeboom, 2010). They are also popular among children and youths. According to Vertonghen and Theeboom (2010), in different Western countries (such as France, the Netherlands, Canada, Finland, Australia and Belgium), martial arts are among the ten mostly exercised sports by children and adolescents. Besides, martial arts are placed in the category of the ten mostly exercised sports in a club setting.

There are more than 100 various styles of martial arts in the world and the most popular ones are of Asian origin, i.e., Judo, Aikido, Japanese Karate, Kung Fu, and Taekwondo (TKD) (Lewis, 1996). There are also other non-Asian martial arts which have become popular nowadays. These include Mixed Martial Art (Bledsoe, 2009), Capoeira (Delamont \& Stephens, 2008), and Krav Maga. TKD, which is the focus of this study, is a traditional Korean martial art that has become an Olympic sport at international level. Though TKD is a native Korean martial art, it has been influenced by the Japanese martial art of Karate and the Chinese martial art of Kung Fu (Khan \& Joshi, 2011, Park, Park, \& Gerrard, 2009; Tausk, 2001; WTF, n.d.). TKD is popular worldwide and it is practiced by more than 30 million people (Park, Park, \& Gerrard, 2009) in some 205 nations including Ethiopia (WTF, n.d.). TKD is also popular among children and adolescents (Park, Park, \& Gerrard, 2009). In this case, it is noted that TKD students begin their TKD career at early ages (Pieter, 2009).

TKD/ martial arts and their role on practitioners' wellbeing have been studied by many researchers. Both quantitative and qualitative studies have been carried out. According to Binder (2007) and Vertonghen and Theeboom (2010), most researchers found positive outcomes of such training. Here, it is important to note that wellbeing could be understood as living or having or experiencing a good life and it could have different dimensions including material welfare, physical health, relationships, living environments, feelings, etc (White, 2008). The positive role of the martial arts found by various researchers could be conceptualized as psychosocial benefits (Goldsmith, 2013; Kurian, Verdi, Caterino, \& Kulhavy, 1994; Lakes \& Hoyt, 2004; Lantz, 2002; Movahedi, Bahrami, Marandi, \& Abedi, 2013; Steyn \& Roux, 2009; Zivin, et al., 2001) and physical benefits (Draxler, Ostermann, \& Honekamp, 2010; Fong, Fu, \& Ng, 2012; Fong, Tsang, \& Ng, 2011; Khan \& Joshi, 2011; Lantz, 2002). There are also other researchers who reported negative outcomes of the martial arts. Such negative outcomes could be seen in terms of injury related problems (Kazemi, et al., 2009; Landa, 2004; Pieter, 2005; Zetaruk et al., 2005), psychosocial problems (Endresen \& Olweus, 2005; Lotfian, Ziaee, Amini, \& Mansournia, 2011), health related problems (Wargo, Spirrison, Thorne, \& Henley, 2007), and unhealthy weight management of athletes (Kazemi, Alima, \& Ciantis, 2011).

As can be seen above, there is inconsistency of research findings regarding the role of martial arts. In addition, most of the studies in this area were conducted outside of the African continent. Meanwhile, no such study was done in Ethiopia, except the other part of this study published earlier (see Tadesse, 2015). Therefore, studying the role of TKD in Ethiopia could be a significant contribution as the nature of the country is quite different from that of other countries in the West and Asia.

Ethiopia is one of the developing countries found in Africa having gross domestic product (GDP) value of $\$ 46.17$ billion and a GDP per capita of $\$ 489.0$. It is an agrarian country where $81 \%$ 
of the population lives in rural areas (United Nations Statistics Division, 2015) and where the agriculture sector covers $43 \%$ of the GDP (CSA, 2009). Ethiopia is also the second largest country in Africa with an estimated population of $96,506,000$. The average annual population growth rate of the country is $2.6 \%$ while the sex ratio (males per 100 females) is 100.1 . The population of the country is predominantly young; $42.1 \%$ of the population is under the age of 15 (United Nations Statistics Division, 2015). Ethiopia is a multi-ethnic country consisting of more than 80 ethnic groups. Besides, societies in the country are predominantly collectivist and patriarchal. According to Levine (2002), Ethiopia is a country where masculinity and warriorhood have been valued and upheld by its people for centuries.

\subsection{Objectives of the Study}

(1) To describe the nature of TKD training which the TKD adolescents had been receiving, in Addis Ababa.

(2) To explore the benefits of TKD training for the wellbeing of adolescents in Addis Ababa.

(3) To identify problems/challenges associated with TKD training and TKD adolescents' wellbeing, in Addis Ababa.

\section{Method}

This research is part of a study done in 2014 to examine the role of TKD training on the wellbeing of adolescents in Addis Ababa city. The other part of the study, which focused on measuring and comparing the subjective wellbeing of TKD and non-TKD adolescents, has already been published (see Tadesse, 2015).

\subsection{Research Design}

This study used a mixed methods research design. Using this strategy of inquiry, both qualitative and quantitative data were collected and collection of data was done concurrently. Mixed methods research is used in this study because of a number of reasons. First, the problem under investigation of this study requires the use of mixed methods. The role of martial arts training is somehow well-studied in other countries. This enabled the researcher to have some insight into the constructs in this area of study to conduct quantitative study. Meanwhile, this research issue was not studied in Ethiopia. This opened a door for qualitative investigation. Second, it is obvious that both the quantitative and the qualitative methods have their own limitations. The quantitative method fails to address subjective aspects of the issue while the qualitative method fails to address the objective dimension. Therefore, conducting mixed methods research enabled the researcher to have the advantage of using the strengths of both methods. Besides, according to Creswell (2009), using this method helps to triangulate results of a study.

\subsection{Study Area}

This study was conducted in Addis Ababa which is the capital city of Ethiopia. According to the City Government of Addis Ababa (2014), Addis Ababa, as a capital city of Ethiopia, was founded in 1886 by Emperor Menelik II and his wife Empress Taytu Betul. According to CSA (2012), the total area of the city is $540 \mathrm{~km}^{2}$ and the projected population of the city in 2012 was 3,048,631, making the population density $5,645.61 / \mathrm{km}^{2}$. The sex ratio (male/female) was $.91: 1$. Agewise, there were 681,170 people under the age of $14 ; 2,228,510$ people in the age group of $15-64$; and 151,716 people above 65 years of age.

Addis Ababa is not only the capital city of Ethiopia but also the seat of different continental and international organizations like African Union and United Nations Economic Commission for Africa (UNECA). The administration of the city is divided into three major hierarchies, i.e., city level, sub-city level, and wereda level (wereda is the smallest administrative unit in the city). The city of Addis Ababa has ten sub-cities and their 116 weredas (City Government of Addis Ababa Bureau of 
Finance and Economic Development, 2013). Addis Ababa is also a city in which different forms of martial arts are exercised by its inhabitants. To observe this, one can simply move around the city. Everywhere in the city, it is common to see banners that advertise different clubs of martial arts and their graduation ceremonies. Most frequently observed types of martial arts in the city are: world and international TKD; different forms of Chinese Kung Fu; and Japanese Karate.

\subsection{Participants}

The quantitative part of the study had 108 TKD adolescent respondents selected using one stage cluster sampling. Of the 53 TKD clubs in Addis Ababa city identified by the researcher, four clubs were selected randomly and all the adolescents in these clubs were included in the study (Tables $1 \& 2$ ) (For details about population of the study, sample size and sampling procedure, see Tadesse, 2015).
Table 1. Age of respondents in different belt levels

\begin{tabular}{lccc}
\hline \multicolumn{1}{c}{ Belt Level } & $\boldsymbol{n}$ & $\mathbf{M}$ & SD \\
\hline Lower level belt & 53 & 14.09 & 1.86 \\
Middle level belt & 26 & 14.92 & 1.99 \\
High level belt & 23 & 15.17 & 1.75 \\
\hline Total & 102 & 14.55 & 1.917 \\
\hline
\end{tabular}

Note: missing values $=6$

Table 2. Sex of respondents by their belt level

\begin{tabular}{|c|c|c|c|c|c|c|}
\hline \multirow{2}{*}{\multicolumn{3}{|c|}{ Characteristics }} & \multicolumn{3}{|c|}{ Belt Level of Respondents } & \multirow{4}{*}{$\begin{array}{c}\text { Total } \\
49(46.2 \%) \\
57(53.8 \%)\end{array}$} \\
\hline & & & Lower level (white, & Middle level & Higher level (red & \\
\hline \multirow{2}{*}{ Sex } & Female & $n(\%)$ & $27(50.0 \%)$ & $10(38.5 \%)$ & $12(46.2 \%)$ & \\
\hline & Male & $n(\%)$ & $27(50.0 \%)$ & $16(61.5 \%)$ & $14(53.8 \%)$ & \\
\hline \multicolumn{2}{|c|}{ Total } & $n(\%)$ & $54(100.0 \%)$ & $26(100.0 \%)$ & $26(100.0 \%)$ & $106(100.0 \%)$ \\
\hline
\end{tabular}

The qualitative part of this study also had 12 participants, i.e., eight TKD adolescents (Table 3 ) and four TKD coaches (Table 4). A non-probability sampling technique of purposive sampling with maximum variation strategy (Cresswell, 2007) was utilized to identify participants for the qualitative part of the study. Accordingly, efforts were made to select two TKD adolescents of different gender and belt levels from each of the four TKD clubs.

Table 3. Characteristics of TKD adolescent interviewees

\begin{tabular}{lcccccccc}
\hline \multirow{2}{*}{ Characteristics } & \multicolumn{7}{c}{ TKD Adolescent Interviewees } \\
\cline { 2 - 9 } & $\mathbf{1}$ & $\mathbf{2}$ & $\mathbf{3}$ & $\mathbf{4}$ & $\mathbf{5}$ & $\mathbf{6}$ & $\mathbf{7}$ & $\mathbf{8}$ \\
\hline Sex & Female & Female & Male & Female & Male & Female & Male & Female \\
Age & 14 & 12 & 15 & 15 & 13 & 18 & 16 & 15 \\
Belt level & 1st Dan & Red & Blue & Blue & Green & Brown & 1 1st Dan & Blue \\
Competition & No & No & No & No & No & No & Yes & No \\
Club & A & A & B & B & C & C & D & D \\
\hline
\end{tabular}

Table 4. Characteristics of TKD coach interviewees

\begin{tabular}{lcccc}
\hline \multirow{2}{*}{ Characteristics } & \multicolumn{3}{c}{ TKD Coaches } \\
\cline { 2 - 5 } & Club A's & Club B's & Club C's & Club D's \\
\hline Sex & Male & Male & Male & Male \\
Age & 31 & 28 & 28 & 29 \\
Belt level & $3^{\text {rd }}$ Dan & $4^{\text {th }}$ Dan & $3^{\text {rd }}$ Dan & $3^{\text {rd }}$ Dan \\
Years as trainer & 13.5 & 8 & 10 & 8 \\
Training in other martial arts & No & Yes* $^{*}$ & Yes $^{* *}$ & No \\
\hline
\end{tabular}

Note: * Jujutsu; ${ }^{* *}$ boxing, Kung Fu, ITF, Dakai'to Ryu

\subsection{Data sources and data collection tools}

The main source of data for this study was primary data. Two tools of data collection were used, i.e., self-administered questionnaire and in-depth interviews. The self-administered 
questionnaire was used for the quantitative part of the study to collect data from adolescents. This questionnaire had both close- and open-ended questions. And it included issues like background information on adolescents, adolescents' perception of benefits of TKD, and adolescents' perception of problems of practicing TKD. The questionnaire was prepared in the English language and administered in the Amharic language.

In-depth interviews were designed to be held with TKD adolescents and their instructors. In both cases, guiding questions were prepared and used. The in-depth interviews which were held with sampled TKD adolescents and coaches focused on issues like their perception of the benefit of TKD and problems of practicing TKD. Coaches were also interviewed about the nature of TKD training. All the in-depth interviews were tape-recorded.

\subsection{Data analysis and presentation}

Both quantitative and qualitative data analyses were conducted in this study by following some steps. In the case of the quantitative part, the first step was data cleaning and management (see, Tadesse, 2015, for details). Meanwhile, for the open-ended questions of the questionnaire, coding was done to identify major themes so that these questions could be analyzed quantitatively. After this, the next step was entering the data into SPSS and checking that the data were properly entered. Then, descriptive statistics was employed to summarize the characteristics of samples. Finally, frequency distributions and percentages were computed for both open-and close-ended questions. Multiple response set techniques were used for questions which allowed multiple responses.

The qualitative data were analyzed following the steps suggested by Creswell (2007). Accordingly, the in-depth interviews were transcribed verbatim, in the Amharic language. Next, the interviews were translated into the English language. After this, the data were read thoroughly to have some insight into the general picture of the situation. Then, coding was done. Significant quotes from interviewees were highlighted and codes were created by grouping similar ideas together. Codes with similar nature were also further grouped together into categories. These categories finally helped to identify fewer themes and patterns. Then, themes and patterns were presented in discussion format. And, finally, these results were interpreted in relation to other research findings and the researcher's personal experience.

The data gained from the quantitative and qualitative methods were presented and discussed in an integrated manner. This helped to compare and contrast specific findings regarding each objective of the study.

Table 5. Summary of methodological triangulation

\begin{tabular}{lll}
\hline Units of analysis & Observation units & Methods of data collection and analysis \\
\hline Nature of the TKD training & A. TKD instructors & $\begin{array}{l}\text { A. In-depth interview } \\
\text { Qualitative analysis }\end{array}$ \\
\hline $\begin{array}{l}\text { Benefits of TKD training for } \\
\text { adolescents }\end{array}$ & $\begin{array}{l}\text { A. TKD adolescent } \\
\text { B. TKD instructors }\end{array}$ & $\begin{array}{l}\text { A. Questionnaire and in-depth interview } \\
\text { B. In-depth interview } \\
\text { Quantitative and qualitative analysis }\end{array}$ \\
\hline $\begin{array}{l}\text { Problems in relation to TKD } \\
\text { training and TKD adolescents' } \\
\text { wellbeing }\end{array}$ & $\begin{array}{l}\text { A. TKD adolescent } \\
\text { B. TKD instructors }\end{array}$ & $\begin{array}{l}\text { A. Questionnaire and in-depth interview } \\
\text { B. In-depth interview } \\
\text { Quantitative and qualitative analysis }\end{array}$ \\
\hline
\end{tabular}

\subsection{Ethical consideration}

In this research, the researcher made efforts to make sure that the ethics of both the profession of social work and professional research are followed and study participants were protected. Accordingly, the researcher maintained: informed consent/assent/permission at different levels; anonymity of participants; confidentiality of information given by participants; and avoidance of possible harm to participants as a result of participating in the study (for details, see, Tadesse, 2015). 


\section{Results}

\subsection{The nature of taekwondo training provided for adolescents}

Based on the data from interviews with TKD coaches, the researcher has come to conclude that the nature of TKD training provided for the adolescents in the four clubs is largely similar. And, it could be summarized in terms of the process of registration and expenses, community services by the clubs, facilities of the gyms, frequency and hours of training, components of the training of TKD, and TKD competition. Though these points are not exhaustive, they provide some insight into the context in which the adolescents practiced TKD.

(1) Registration and expenses. After adolescents/their parents decided that the adolescents should join the TKD training, the next step taken is getting the adolescent registered for the training and making them members of TKD clubs. In this case, there are some expenses that should be covered by the adolescents/their families. The first expense is that of registration fee and paying the first monthly membership fee. For example, in club D the registration fee was 20 Birr $(\$ 1)$ per new student. Monthly membership fees for adolescents in the four participant clubs ranged from 50 Birr (\$2.5) per month in club B to 80 Birr (\$4) per month in the rest of the clubs. Monthly membership fees for adults were usually higher, for example, 100 Birr (\$5) per month in club C and D. Students were also expected to wear the white TKD uniform called dobok, in trainings. The uniform could cost some 350 Birr $(\$ 17.5)$. However, new students were not usually required to have uniforms immediately after registration. In the case of belt promotion/graduation, students were also required to pay different amounts of money for different belt levels and their corresponding certificates. For example, in club A, the payment ranged from 150 Birr (\$7.5) (when passing to yellow belt) to 450 Birr (\$22.5) (when passing to second degree black belt). Here it should be noted that, according to UN-HABITAT (2008), most of the employed households in Addis Ababa got a monthly income of no more than $\$ 68$.

(2) Community service. It was noted that all of the participant clubs of the study participated in a community service. This community service had been given in two major ways. One way is by training some students for free, in regular trainings. It was noted that all of the four clubs had some students whom the coaches did not require to pay anything for the abovementioned expenses, because the students and their families were unable to do so. In this case, for example, club B's coach said, "I train many for free as they are not able to pay. The parents of the kids come and ask me. I live around here and I know their status, the kind of job they do. When they ask me, I say 'no problem' and I train their kids" (31/5/2014). The second way of giving community service is associated with summer time voluntarism, in which all the four clubs train children and adolescents for free. Club C's coach said, "My club gives a kind of community service in Arada sub-city. During summer time, we select some 20 girls and teach them self-defense" (2/6/2014).

(3) Gym facilities. The gyms of the four clubs differed, among other things, in terms of availability of facilities like toilet, shower, mats, and space for training. These facilities are very important since they contribute to the comfort and wellbeing of the trainees. The facility of toilet was available in three of the clubs (A, B, and D). Shower was available only in two of the clubs (A and $B$ ). Three of the clubs (A, B, and C) had some kinds of mats to cover the floors of their gyms. The mat in club B was the best of all since it is a kind of mat used in TKD competitions; it is thicker. There was no mat in club $C$, the floor of the club was of timber. In the case of space available for the training, club B and C had huge spaces that could allow approximately $50-70$ adolescents freely practice at a time. The spaces of the gyms of club A and D were narrower and could not allow more than 25 students at a time, restricting free movement of students.

(4) Frequency and hours of training for adolescents. In all clubs, usually children and adolescents came to their clubs' gyms and practiced TKD three days per week - Friday (in the afternoon, after school), Saturday, and Sunday. These three days were chosen for training to engage adolescents in TKD during their free time so that their formal education remains unaffected. In the case of hours of training, each session of the training usually took one and half hours with breaks in between exercises. In relation to this, it has been noted that in all clubs there were efforts to provide the trainings based on the age of trainees. In three of the clubs (A, C, and D), trainees below the age of 18 were trained separately from adults who were above 18 years. A more 
compartmentalized training was found in club B where there were separate training schedules for trainees in the age categories of eight-12, 13-16, 16-18, and $>18$.

(5) Components of the training of Taekwondo. There were different components of the TKD training identified by the coaches of TKD. These components include Warming up (stretching, running, etc) exercises; fitness/strength exercises; techniques of TKD (stances, blocking techniques, and kicking and punching techniques with and without pads); sparring; form practices; breaking; meditation and breathing; philosophy and ethics of TKD; self-defense; and trainings for demonstration/graduation ceremonies. Though there were many components of the training of TKD, all of the coaches agreed that most of the focus of their training of TKD was directed at sparring trainings, followed by form training. Here, it is important to note that warming up exercises, fitness exercises, and techniques of TKD are inseparable parts of both the sparring and form trainings. According to all the coaches, too much attention is given to sparring training because world TKD is now a very popular competitive sport that has competitions at local (club, school, sub-city), national (all Ethiopian games), continental (all African games), and international (e.g., Olympic) levels. All coaches also claimed that form practice was given second-place emphasis because it did not have any national competition. Instead, it was mainly used for the sake of promotional tests. Club C's coach describes this situation:

In our club, the inclination is toward sparring. The main reason for this is that, these days all the TKD competition in Ethiopia is of sparring. Formerly, TKD form competitions were being held. Now, there is no form competition because there is no uniformity in terms of TKD forms among the clubs of TKD in Ethiopia (2/6/2014).

There was also unanimity among the four clubs on other three points. The first is that when the kicking and punching techniques are compared, most of the emphasis was placed on the kicking ones. In other words, as club A's coach put it, "...90\% or $80 \%$ of what we do is with legs" $(14 / 5 / 2014)$. The second point is that the clubs prepared for and presented demonstration shows usually once a year for the purpose of graduation ceremonies. Activities for graduation ceremonies included among other things, demonstration of forms, breaking (e.g., timber), and self-defense and/or choreographed fights. The third point is that breaking trainings were not considered as a major component of the training of TKD, but as trainings only done during preparation times for demonstration.

In the case of other components of TKD training, different coaches differed in terms of giving different degrees of attention. With regard to meditation and breathing, two of the coaches (club A and D) said that meditation and related breathing exercises are non-existent in their clubs, while the rest two (club B and C) claimed that it is given in their clubs to a limited degree. In club B it is claimed to be practiced once in a month among the highest belt holders. In club $\mathrm{C}$, the coach said there was no serious and regular meditation for colour belts (belts below black), but simple breathing exercises. In case of the philosophies and ethics of TKD, it was evident that in all the four clubs there was no regular or formal lecturing of the philosophy of TKD (in relation to the interaction of humans and nature, the presence of opposing forces in the universe, and the need for balance in universe, etc). However, ethical principles are somewhat taught. The rules of conduct in the gyms were clearly understood by trainees in all clubs, in one way or in another (for example, by lectures of the coach, notices posted, by observation of the behavior of the coach and other senior students, and by asking other senior students/coaches). These rules covered the students' behavior starting from entering the gym to leaving the gym. Some of the rules include: taking off one's shoes before entering the gym; respecting and obeying the coach and other senior students; and saluting the gym, the flags (of Korea and Ethiopia), the coach, and other students.

Aside the above specific behavioral codes in the gym, it seems that only two of the clubs (club B and D) gave more emphasis to seriously lecturing the ethics of TKD. In club B, the coach said he taught the 11 ethical principles of TKD every Saturday, at the end of the day's training session. In club D, the coach claimed that he taught the principles of TKD every time he got the chance.

In the case of self-defense trainings, in two of the clubs (club A and D), no separate selfdefense trainings were provided for the adolescents, but all the trainings of TKD (including sparring and forms) were considered to enable students defend themselves. In the other two clubs (club B 
and C), specific self-defense techniques were taught to adolescents. However, they were not emphasized as much as sparring and forms; they were taught sometimes and irregularly. Here it is important to note that the clubs which provided some sort of self-defense training were the ones whose coaches had exposure to other martial arts.

(6) Taekwondo sparring competition. All of the four clubs participated in TKD fight competitions at local or national levels. In Ethiopia, TKD competitions are based on mainly three criteria or categories, i.e., sex, age, and weight categories. Competitors within the same sex and age category are matched based on weight. There are three different age categories - adult category (>18 years), under 17 (16-17 years), and under 15 (14-15 years). Competition in the adult category existed for longer time. However, the under 17 competition was started recently and the under 15 competition was about to be started for the first time when data was collected for this study (it was scheduled to be held in July 2014). Another thing learned is that the government of the country has recently set up a training academy to train adolescents (under 17 years-old) for competitions in different sports, including TKD.

\subsection{Taekwondo Adolescents' and Coaches' Perception of the Benefits of TKD for adolescents}

In both the quantitative and qualitative parts of this study, attempts were made to understand TKD adolescents' and coaches' perception of benefits of practicing TKD for adolescents. All participants were allowed to give multiple responses for the question regarding the benefits of TKD. Accordingly, six themes were identified. These themes are: social benefits; physical benefits; mental benefits; self-defense; addiction avoidance; and other benefits.

Within each theme, participants mentioned specific benefits. For example, social benefits include: more friends; good social relations with others; and prosocial behaviors (respecting others, sociability, discipline, obedience, patience, good attitude toward others). Physical benefits also involve: disease prevention (e.g., common cold); improved health; good physical appearance; and physical fitness (vitality, speed, strength, muscle, endurance). Mental benefits are: self-confidence; mental satisfaction; improved thinking and reasoning; wisdom; courage; happiness; sense of freedom; and self-awareness. Addiction avoidance was expressed in terms of distancing oneself from abusing substances and unnecessary places that lead to substance abuse. Other benefits are expressed as improvement in education, participation in competition, new skills, and opportunity to teach.

The quantitative part of the study used a multiple response set technique to compute frequency distributions and percentages for adolescents' perception of the benefits of TKD. Of the total 108 TKD adolescents, 107 gave their answers for this question. In this case, as shown in table 6 , the number of responses was 223. This increased the percent of cases (respondents) from 100 to 208.4. As can be seen from the table below, the most mentioned themes are social benefits, physical benefits and mental benefits.

Table 6. TKD adolescent respondents' perception of the benefits of TKD

\begin{tabular}{lcc}
\hline \multicolumn{1}{c}{ Adolescents' perception of the benefit of TKD } & $\boldsymbol{n}$ & $\mathbf{\%}$ \\
\hline Mental benefits & 54 & $50.5 \%$ \\
Self-defense & 29 & $27.1 \%$ \\
Physical benefits & 55 & $51.4 \%$ \\
Addiction avoidance & 7 & $6.5 \%$ \\
Social benefits & 57 & $53.3 \%$ \\
Other benefits & 21 & $19.6 \%$ \\
\hline Total & 223 & $208.4 \%$ \\
\hline Note: \% = \%ith respect to the total number of respondents $(n=107)$
\end{tabular}

A similar pattern of response is also observed among the responses of the eight TKD adolescent interviewees. The most frequently mentioned themes, in this case are: social and physical benefits, each by five students; mental benefits, by three students; self-defense, by two students; and other benefits, by one student. Addiction avoidance was not mentioned. In the case of social benefits, one of the male adolescents said: 
To tell you the truth, I was a very difficult boy. Even when people drank coffee at our house, I used to disturb them. But, now I have improved. My family members tell me that my behavior has improved. They tell me not to quit TKD... It is just TKD itself [What contributed for this change]. And, I have special place for my Master; it is his influence (Interviewee 3, 31/5/2014).

Most of the interviewee adolescents mentioned more than one benefits of TKD for their wellbeing. For example, interviewee six (female) said, "It increased my self-confidence; it made me happy; it improved my health; and it enabled me to have a good physical appearance" (7/6/2014). Another female adolescent also claimed:

I have got many benefits. For example, before I started TKD, the boys in my school used to hit me. But now, I am able to defend myself... In addition to self-defense, I have come to have better discipline or behavior. Formerly, I used to insult other people, but now I have come to be calm. (Interviewee 2, 8/6/2014).

In the case of coaches' perception of the benefits of TKD, two different patterns of response are noticed. The first difference is in the order of frequently mentioned themes. Three themes, i.e., addiction avoidance, physical benefits, and mental benefits are mentioned more frequently, each by three coaches. Social benefit is mentioned only by two coaches. Other benefits (e.g., for education) is mentioned only by one coach. The other difference is regarding self-defense. Surprisingly, selfdefense is not mentioned at all by the four coaches. Regarding the benefits of TKD for adolescents, club C's coach asserted:

I can mention a lot of benefits of TKD for adolescents, if we like. It improves their consciousness and alertness. This in turn contributes for their education - to study effectively, concentrate, etc... The benefit of TKD and any other sport for health is obvious... I have seen many adolescents who were previously unable to eat well, change and start eating. There is also one unique adolescent, who came to my club some 5 years ago and who was unable to walk normally because his heels didn't touch the ground. He was advised by a physician to do sports like TKD. Today, this adolescent walks normally like other adolescents... TKD is also important for this generation in terms of teaching them discipline and respect... it also protects them from exposure to drug addiction. Every neighborhood you go, almost all adolescents smoke cigarette and chew khat [a stimulant herb]. But when they join TKD training, they won't do so. Those who begin doing TKD earlier will not be exposed to such addictions $(2 / 6 / 2014)$.

\subsection{Adolescents' problems associated with practicing TKD}

The problems associated with practicing TKD are presented in two subsections. The first subsection deals with TKD adolescents' and coaches' perception of problems associated with practicing TKD for adolescents. And, the second subsection presents problems related with TKD sparring competition.

\section{(1) Taekwondo adolescents' and coaches' perception of problems.}

In both the quantitative and qualitative parts of this study, efforts were made to understand the perception of TKD adolescents and coaches about the problems of practicing TKD. In this case, all participants were allowed to give multiple responses. As a result, four themes were identified. These themes are: family-related problems; injury; community-related problems; and miscellaneous problems. Here, it is important to note that majority of the adolescent respondents claimed that they faced no problem at all.

Various specific problems were mentioned in each of the themes identified. For instance, family-related problems involve: parents' lack of awareness; lack of money to cover expenses; and disagreements with parents (who tell their adolescents to quit training for different reasons, especially to emphasize education). Community-related problems include: negative attitude toward martial arts and martial artists (considering it as a violent activity, believing it is dangerous for female virginity, fearing practitioners) and provocation by peers (mocking, challenging to fight, insulting). Injuries that are mentioned by respondent are mostly simple and include minor leg 
injuries, bumps, bruises, strains, etc. Miscellaneous problems involve: busy schedule of adolescents; lack of TKD materials and other facilities; far distance from home to clubs; and lack of balanced diet.

The quantitative part of the study used a multiple response set technique to compute frequency distributions and percentages for adolescents' perception of the problems. Of the total 108 TKD adolescents, 99 gave their answers for this question. In this case, as shown in table 7 below, the number of responses is 103. This increased the percent of cases from 100 to 104.

Table 7. TKD adolescents' perception of the problems of TKD

\begin{tabular}{lcc}
\hline Adolescents' perception of problems of TKD & $\boldsymbol{n}$ & $\mathbf{\%}$ \\
\hline Family-related problems & 17 & $17.2 \%$ \\
Injury & 7 & $7.1 \%$ \\
Community-related problems & 8 & $8.1 \%$ \\
Miscellaneous problems & 8 & $8.1 \%$ \\
No problem & 63 & $63.6 \%$ \\
\hline Total & 103 & $104.0 \%$ \\
\hline Note: $\%=$ \% with respect to the total number of respondents $(n=99)$
\end{tabular}

From the interview with the eight TKD adolescents, a somewhat different pattern of response emerged. The most frequently mentioned themes by adolescents were: communityrelated problems, by four adolescents; family-related problems, by two adolescents; no problem at all, by two adolescents; injury (during sparring training), by one adolescent; and miscellaneous problems (rapid weight loss), by one adolescent. Explaining the problems, interviewee four said:

I mean, I haven't faced any problem in TKD itself. But, some kids who know that we practice TKD provoke us on the street...Both males and females do so...I mean, when we walk on the streets, they ridicule us... I do not tell my school friends that I practice TKD, because I have seen what happened to me in my neighborhood as a result of telling people about my participation in TKD training $(31 / 5 / 2014)$.

Another adolescent also described the problems he faced in relation to injury and community-related problems:

Yes, I had once injured my hand. It happened while we were sparring in training; we were using powerful strikes. But, I recovered immediately...They [neighborhood peers] mock me saying, 'is this the way you do TKD? We can beat your TKD with one stone' (Interviewee 5, 7/6/2014).

In the case of the coaches' perception, one theme is mentioned more frequently. This theme is community-related problem (mentioned by three coaches). Within this theme, two specific issues were mentioned repeatedly, i.e., provocation by peers and incorrect societal attitude toward TKD. Talking about provocation, club A's coach said, "they provoke my students saying...'stone also has a black belt' or 'for those who wear TKD black belts, we also have black stones'” (14/05/2014). In relation to incorrect societal attitude toward TKD, club C's coach argued:

Like in other aspects of a society's life, female students of martial arts are victims of discrimination. For example, one reason why parents do not send their female children to the martial arts training is associated with fear of losing virginity, as a result of doing flexing exercises like splits. People in our society think like this $(2 / 06 / 2014)$.

Besides community-related problems, two miscellaneous problems were also mentioned by the coaches, i.e., lack of facilities (like shower) and lack of sufficient diet. Regarding diet, club D's coach asserted:

When a person does sport, there are many things that should be fulfilled. The food a normal sportsman eats should be different from others. The main problem is this thing. The families prepare food in their capacity...there are also easy foods affordable by most people, like boiled potato or corn bought from the sides of the streets. But, would that be balanced diet? Would it help? If balanced diet cannot be secured, the kids might get overly skinny and this might have an impact on their growth $(25 / 5 / 2014)$. 
One of the coaches also argued that what determines whether TKD has negative effect or not (especially regarding education) is the role of the coach:

As I already told you, the students respect and fear you [the coach] more than they respect and fear their parents. There could be ways by which you, as a coach, could hurt them. If you always require them to focus only on the TKD training, increasing the intensity of the training, they will perform low in their education. The best thing to do is to put some restriction on their training and to encourage them to focus not only on TKD but also on their education (club C's coach, $2 / 06 / 2014)$.

\section{(2) Problems in relation to TKD Competition.}

It seems that there are various ways by which TKD competition in Ethiopia could negatively influence the wellbeing of adolescent competitors. These ways could be summarized as: adolescents competing in adult categories; poor infrastructure in TKD competitions; injuries; and unhealthy weight management.

In spite of the presence of different age categories, all of the coaches have admitted that they entered adolescents below 18 years of age into the adult category of sparring competitions. For instance, club A and D, entered adolescents as young as 16, club B entered adolescent as young as 15 , and club $\mathrm{C}$ entered adolescents as young as 17 . The coaches reasoned that they did so because they knew their students' capacities in terms of biology (muscle and bone strength) and skill (technique, speed, etc). Similarly, while holding a black belt is the minimum requirement for participating in adult category, except club A, all others entered students below the rank of black belt (including adolescents) into adult competition. The same reasoning is applied here by the coaches.

The poor infrastructure of TKD competition in Ethiopia can be understood in terms of: poor quality of protection equipment; absence of trained physicians; and absence of ambulance during competitions. According to club C's coach, excepting the highest national level competitions, these problems are commonplace in Ethiopia. He described the protection equipment as either "outdated" or "forged" and unable to sufficiently protect athletes from injuries. He also said that in all local competitions he watched, there were no physicians assigned. Instead of physicians, physiotherapists of soccer players were there. With regard to ambulance service, he said, "What has been done during this kind of situation is that we just ask for the help of individuals who have cars and take the injured athlete to a hospital" (2/6/2014).

Unhealthy weight management could be understood as an athlete's effort to lose or gain weight within a short period of time. The practice of rapid weight reduction was more prevalent than rapid weight gain. These practices had been performed by all clubs. Here, note that club A's coach claimed such practices did not happen at his club, but some of the adolescent respondents in his club reported the opposite. Two of the coaches reasoned that the main reason for unhealthy weight management to happen was that students did not listen to their coaches or they did not always get ready.

Despite all the above-mentioned undesirable situations surrounding sparring competitions, all the coaches/clubs reported that there had never been any serious injury on their athletes. In this case, club C's coach said that serious injuries usually did not occur as a matter of luck rather than any other reasons $(2 / 6 / 2014)$. Nevertheless, two of the coaches said that their athletes caused serious injuries to other clubs' athletes.

TKD adolescent participants of this study (both in the quantitative and qualitative parts) were also asked whether they had participated in TKD completions and whether they got injured and whether they unhealthily managed their weight.

Of the eight TKD adolescents who participated in the interviews, only one of them said he had participated in a competition. This interviewee also said that he did not face any major injury. But, though he did not see it as a problem, he admitted to have made an effort to reduce his weight so that he could fit into a particular weight category. 
I had reduced my weight. I did so by wearing plastic [inside his cloths] and doing exercises like running and other footwork exercises. I began doing so 15 days before the competition. And, I did it every day till the time of weigh-in, which was at the eve of the competition. And, I achieved it. I lost seven kilos. I normally gain weight easily, that is why I had to lose all these seven kilos (interviewee 7, 14/6/2014).

From the quantitative results, majority of the respondents said they did not participate in fight competitions. Of the 106 adolescents who responded to this question, only 27 (25.5\%) participated in fight competition. Those adolescents who said they participated in fight competitions $(n=27)$ were further asked to tell whether they experienced injuries as a result of the competitions. Twenty six of them answered this question. Most of the respondents, 16 (61.5\%), did not experience injuries while ten (38.5\%) experienced injuries. These same respondents who said they participated in fight competitions $(n=27)$ were also further asked to tell whether they rapidly lost or gained weight for competition purpose. Twenty four of them answered this question. Majority of them, 18 (75\%), experienced unhealthy weight management while the rest, six (25\%), did not.

\section{Discussion}

\subsection{The nature of TKD training}

In this sub-section it is worth emphasizing two specific points. The first is regarding the gender gap in World TKD and the second is about the components of the training of TKD. The gender gap in World TKD could have two different dimensions, i.e., with regard to TKD adolescents and with regard to TKD coaches. As discussed in the previously published part of this study (Tadesse, 2015), the gender gap among TKD adolescents is very narrow while the opposite is true in the case of TKD coaches. In the case of the components of the TKD training, it is essential to identify the different aspects of the training and learn which aspects are emphasized more by coaches. Doing so helps, among others, to determine whether the training is more of traditional or modern/sport TKD. This in turn is important because there are controversies regarding which type of martial arts is better for wellbeing. In this case, traditional martial arts are usually considered better (see, Binder, 2007; Nosanchuk \& MacNeil, 1989; Trulson, 1986).

TKD has different components of its training. Generally, the different aspects of its training include: warming up and stretching exercises; physical fitness exercises; techniques of TKD (stances, kicking, blocking, and punching); meditation and breathing; philosophy and ethical principles; form/pattern trainings; self-defense trainings; sparring/fight training; and breaking techniques (Park, Park, \& Gerrard, 2009; Tausk, 2001; Trulson, 1986). Almost all of the components of TKD mentioned above were identified in this study to be integral parts of the training of TKD in Addis Ababa, Ethiopia.

However, not all the components of the training are equally emphasized by all schools of TKD in the world and in Ethiopia. In this regard, according to Tausk (2001) and Trulson (1986), there are two types of TKD, i.e., modern/sport TKD and traditional TKD. The sport/modern TKD is characterized by its emphasis on competition and winning. On the contrary, in traditional TKD, the focus is on self-defense and manipulation of vital points of the body; pattern training; meditation, teaching the philosophy of TKD, and both hand and foot techniques.

From the results of this study, the researcher has come to conclude that, overall, the TKD training provided for adolescents by the four participant clubs was more of a modern/sport TKD than traditional TKD. This is because, most of the training in the four clubs concentrated on fight competitions and little attention was given to other aspects of TKD such as pattern practices, selfdefense, meditation, philosophies and ethics of TKD, and hand techniques. Here it is important to note that the researcher is not saying that the trainings in the four clubs were identical and purely sport/modern TKD. The researcher believes that instead of dichotomizing the training of TKD as modern or traditional, we should understand it as a modern/traditional continuum. In this case, the researcher asserts that, though somewhat different, all the four clubs are found toward the modern end of the continuum. 


\subsection{The benefits of TKD training}

Results of the study showed that both TKD adolescents and coaches perceived that practicing TKD has multifaceted benefits for the wellbeing of adolescents. These benefits were classified into six themes: social benefits; physical benefits; mental benefits; self-defense; addiction avoidance; and other benefits. Within each theme, various specific benefits of TKD were identified. Social benefits include: good social relations; more friends; sociability; and other prosocial behaviors like respecting others, good attitude toward others, discipline, obedience, and patience. Physical benefits include: disease prevention; vitality; speed; strength; muscle; physical appearance; and endurance. Mental benefits involve: self-confidence; mental satisfaction; improved thinking and reasoning; concentration; wisdom; courage; happiness; sense of freedom; and selfawareness. Addiction avoidance includes: distancing oneself from abusing substances and unnecessary places that lead to substance abuse. Other benefits involve: improvement in education; chance to compete; new skills; and opportunity to teach.

As it can be understood from the results of this study, social, physical, and mental benefits are the three most frequently mentioned responses by adolescents. Meanwhile, given TKD is a martial art, it is surprising to learn that self-defense is not frequently mentioned as a benefit of TKD. This situation might be attributed to three possible causes. One is that self-defense is not mentioned frequently because its contribution for adolescents is too obvious to tell. The second reason could be that, in fact, the primary benefits gained from TKD are other than self-defense. And, finally, it may be a reflection of the low level of emphasis given to self-defense in the participant clubs.

Overall, the above-discussed results of this study are in agreement with the findings of other similar investigations. We could broadly divide the positive outcomes of the martial arts/TKD found by other researchers as physical and psychosocial benefits. In the case of physical benefits, it was found that martial arts/TKD improves: flexibility, explosive power, and strength of boys (Khan \& Joshi, 2011); sensory organization and balance of children with developmental coordination disorder (Fong, Tsang, \& Ng, 2011); adolescents' development of postural control and vestibular function (Fong, Fu, \& Ng, 2011); and health-related quality of life (Draxler, Ostermann, \& Honekamp, 2010).

In the case of psychosocial benefits, Binder (2007), in a review of studies regarding the effect of martial arts, concluded that participation in the martial arts is negatively associated with anxiety, aggression, hostility, neuroticism, and feeling vulnerable to attack; while it is positively related with self-confidence, independence, self-reliance, self-control, self-esteem, and easy-going and warm-hearted personality. Many other studies also support the positive outcomes of martial arts/TKD: lower verbal aggression and hostility and higher personal growth and self-acceptance (Steyn \& Roux, 2009); greater improvements in cognitive self-regulation, affective self-regulation, prosocial behavior, classroom conduct, and performance on a mental math test (Lakes \& Hoyt, 2004); self-reliance and enthusiastic optimism (Kurian, Verdi, Caterino, \& Kulhavy, 1994); less participation in risk behavior (Goldsmith, 2013); improvement in social dysfunction of children with autism spectrum disorder (Movahedi, Bahrami, Marandi, \& Abedi, 2013); and improvement of juvenile delinquents on resistance to rules, impulsiveness, and inappropriate social behavior (Zivin, et al., 2001).

Finally, it is important to note that findings of studies of martial arts usually attribute the positive effects they found to a large presence of traditional elements and vice versa (Binder, 2007; Nosanchuk \& MacNeil, 1989; Trulson, 1986). Contrary to this, the findings of this study showed that the TKD training provided for adolescents in Addis Ababa, in spite of being a modern TKD, has positively contributed for the wellbeing of its practitioners.

\subsection{Adolescents' Problems Associated with Practicing TKD}

The TKD training provided for adolescents is not without actual and potential problems. Results of this study showed that majority of the TKD adolescents and their coaches believed that practicing TKD by itself does not have any problem on the wellbeing of adolescents. For example, $63.6 \%$ of the respondents in the questionnaire said they did not face any problem as a result of 
practicing TKD. However, the rest of the respondents and the interviewed TKD adolescents and coaches identified problems that are either directly or indirectly related to TKD. Based on this, four themes were identified: family-related problems; community-related problems; injury; and miscellaneous problems.

Specific problems in each theme were mentioned by participants. Family-related problems include: lack of awareness; lack of money to cover expenses; and disagreements with parents. Community-related problems involve: incorrect or negative attitude toward martial arts and provocation by peers (mocking, challenging to fight, insulting). Minor injuries (like leg injuries, bumps, bruises, muscle strain) were also mentioned by respondents. Finally, miscellaneous problems such as busy schedule of adolescents, lack of TKD materials, far distance from home to clubs, and lack of balanced diet were identified.

The two major themes identified from adolescents' and coaches' perceptions of the problem are community- and family-related problems. The researcher thinks these findings are unique to this study, as most of the findings of other studies emphasized or found problems within TKD itself or practitioners themselves. For example, different studies found the following negative effects: increased youth anti-social behavior (Endresen \& Olweus, 2005); more health concerns among black belts (Wargo, Spirrison, Thorne, \& Henley, 2007); higher anger rate in adolescents (Lotfian, Ziaee, Amini, \& Mansournia, 2011); large increase in aggressiveness and greater tendency to delinquency of adolescents in modern TKD, but in the traditional TKD (Trulson, 1986); and association between aggressiveness and belt level in modern martial arts, but in the traditional martial arts (Nosanchuk \& MacNeil, 1989).

Nevertheless, the specific questions regarding TKD competition and its problems ended up showing other problems that were not perceived by adolescents and coaches. From the quantitative results, it is learned that minority of the respondents $(25.5 \%)$ participated in fight competition. It seems that there are various ways by which TKD competition in Ethiopia could negatively influence the wellbeing of adolescent competitors. These ways could be summarized as: adolescents competing in adult competitions, poor infrastructure in TKD competitions, injuries, and unhealthy weight management.

All coaches admitted that they entered adolescents below the age of 18 into adult category of fight competition. They claimed that they did so because they knew their students' capacities. However, this action could be problematic and could pose a threat to the wellbeing of the adolescents. Here, the adolescents are being made fight with opponents with generally equivalent skill but age. Adults are physically stronger, wiser and more experienced than adolescents, and in this case, adolescents could be hurt. In relation to this, Buckle (n.d.) asserts that mismatching students or competitors in fight could be considered as a physical abuse.

Poor infrastructure in TKD competitions was reported to be present in all competitions except the highest level national competitions. This situation can be understood in terms of poor quality of protection equipment, absence of trained physicians, and absence of ambulance during competitions. Protection equipment, physicians, and ambulance services are essential to prevent and reduce injuries that could happen to competitors. However, they were not fully available, posing a huge threat on the wellbeing of the competitors. One reason for this could be the economic condition of the country which might not be able to afford such facilities. Another reason for this could be the negligence or inactivity of those people who organize the TKD competitions.

In the case of injury, of the adolescents who participated in fight competitions, $38.5 \%$ experienced injuries. This means the number of competitors who did not encounter injuries is larger than those who did. Similarly, all the coaches reported that there has never been any serious injury on their athletes, but minor injuries like bruises and bumps. Meanwhile, all coaches did not witness or heard of any death in TKD fight competitions in Addis Ababa/Ethiopia. These findings could be surprising because of two major reasons. First, in fight competition it seems that major injuries are inevitable since the aim of the competition is to execute powerful kicks and punches against the opponent. Second, low level of injury occurred in a context where there were undesirable situations surrounding fight competitions (mismatching, poor infrastructure, unhealthy weight management). In relation to this one longitudinal study Birrer (1996, cited in 
Landa, 2004) found that injury rates in the martial arts were low in general while sparring was the main reason of injuries in TKD and karate.

The literature also shows us instances of death and serious injuries in the martial arts. Landa (2004), states that though very rare, death occurred in some martial arts competitions, i.e., in boxing and Muay Thai. Nevertheless, injuries are more common and could include: brain injuries, broken bones, tears of the knees, sprains of the shoulders and ankles, cuts and bruises, bloody noses, and assorted infections. Pieter (2005) studied the literature regarding injuries of children in the martial arts. It is found that in TKD more injured parts of the body are the lower extremities and sprains. Kazemi et al. (2009) also conducted a retrospective longitudinal study of injuries in TKD competitions. Results showed that the three most frequently injured body parts are the head, the foot, and the thigh. Most common injuries are contusions, sprains, and strains. Finally, the researchers concluded that TKD competitors below the age of 18 are more likely to be injured in competitions.

Unhealthy weight management (rapid weight loss or gain for the sake of competition) is another problem evident in TKD. TKD athletes could do so for two main reasons. First, it is to return to their normal weight category, when they lose their shapes. The second reason is to be fit into a particular weight category that is supposed to be advantageous to win. Of the adolescents who participated in fight competitions, 75\% experienced unhealthy weight management, especially weight reduction. This practice has been performed by all of the four clubs. This figure indicates that this problem is prevalent in TKD, in Addis Ababa. In line with this, Kazemi, Alima, and Ciantis (2011), asserted that rapid weight reduction is a common practice among TKD athletes, usually to be fit for a lower weight category (than one's natural weight).

However, it seems that most of the coaches and the students in the current study did not consider it as a problem. Two of the coaches reasoned that the main reason for this to happen was that students did not listen to their coaches to always get ready or maintain their weight. Nevertheless, the coaches failed to stop this activity. Different authors in the literature consider this action as a serious problem. For example, Buckle (n.d.) claims that pushing students to cut weight can be considered as a form of physical abuse. Based on this, we can argue that failing to prevent adolescents from rapidly losing or gaining weight could be considered the same. Kazemi, Alima, and Ciantis (2011) also stated that rapid weight loss can result in negative biological effects such as tension, dizziness, headaches, and confusion. Even worse, the same study showed that though athletes engage in such activities to get advantages and to win, this practice was not found to indicate who would win in junior (14-17 years old) TKD athletes competition.

\section{Implication and conclusion}

The results of this study showed three important points, i.e., the nature of TKD training in Addis Ababa City, the benefits of TKD training for adolescents, and problems on adolescents' wellbeing as a result of practicing TKD. The type of TKD training provided for adolescents by TKD clubs in Addis Ababa was more of a modern/sport TKD. Traditional aspects of TKD (self-defense, meditation, philosophy, form, etc) are somehow neglected. The researcher believes that it would be more beneficial for adolescents if coaches and clubs of TKD emphasized the traditional elements in their training. The study also showed that adolescents could benefit from practicing TKD in multiple ways (socially, physically, mentally). Therefore, professional helpers who work with adolescents (social workers, psychologists, etc) may consider using TKD as intervention strategy to help adolescents develop positively.

Some problems were also identified in this study with regard to the training of TKD and adolescents' wellbeing. The problems include family-related problems, community-related problems, poor infrastructure of TKD competition, adolescents competing in adult categories, injury, and unhealthy weight management. In this case, efforts should be made by concerned bodies (families, coaches, TKD federations, the government, etc) to address such problems.

All in all, based on the results of the study, the researcher concluded that the training of TKD in Addis Ababa city was beneficial for adolescents' wellbeing. 


\section{References}

Binder, B. (2007). Psychosocial benefits of the martial arts: Myth or reality? A literature review. Retrieved from http://userpages.chorus.net/wrassoc/articles/psychsoc.htm

Bledsoe, G. H. (2009). Mixed martial arts. In R. Kordi, N. Maffulli, R R. Wroble, \& W. A. Wallace (Eds). Combat sports medicine (pp. 323-330). London: Springer.

Buckle, M. (n.d.). Preventing child abuse in Judo. Retrieved from http://judoinfo.com/menu.htm

City Government of Addis Ababa. (2014). Addis Ababa.

City Government of Addis Ababa Bureau of Finance and Economic Development. (2013). Socioeconomic profile of Addis Ababa for the year 2004 E.C/2011/12G.C. Addis Ababa.

Creswell, J. W. (2007). Qualitative inquiry and research design: Choosing among five approaches (2nd ed.). Thousand Oaks, CA: SAGE Publication.

Creswell, J. W. (2009). Research design: Qualitative, quantitative, and mixed methods approaches (3 ${ }^{\text {rd }}$ ed.). Thousand Oaks, CA: SAGE Publication.

CSA. (2009). Statistical abstract of Ethiopia. Addis Ababa, Ethiopia.

CSA. (2012). Ethiopia demographic and health survey. Addis Ababa, Ethiopia.

Delamont, S. \& Stephens, N. (2008). Up on the roof: The embodied habitus of diasporic Capoeira. Cultural sociology, 2(1), 57-74. doi: 10.1177/1749975507086274

Draxler, T., Ostermann, H., \& Honekamp, W. (2010). Relationship between Asian martial arts and health-related quality of life in Germany. Journal of Public Health, 19(1), 57-64. doi: 10.1007/s10389-010-0343-9

Endresen, I. M., \& Olweus, D. (2005) Participation in power sports and antisocial involvement in preadolescent and adolescent boys. Journal of Child Psychology and Psychiatry, 46(5), 468478.

Fong, H. S., Tsang, W. W., \& Ng, G. Y. (2011). Taekwondo training improves sensory organization and balance control in children with developmental coordination disorder: A randomized controlled trial. Research in Developmental Disabilities, 33(1), 85-95. doi:10.1016/j.ridd.2011.08.023

Fong , H. S., Fu, S., \& Ng, G. Y (2012). Taekwondo training speeds up the development of balance and sensory functions in young adolescents. Journal of Science and Medicine in Sport, 15(1), 6468. doi:10.1016/j.jsams.2011.06.001

Goldsmith, A. S. D. (2013). Adolescent participation in traditional martial arts: Effects of training on risk behaviors and psychological wellbeing. ProQuest Dissertations \& Theses. Retrieved from http://archives.llu.edu/cdm/ref/collection/lludis/id/17889

Green, T. A. (Ed.) (2001). Martial arts of the world: an encyclopedia. California: ABC-CLIO.

Kazemi, M., Chudolinski, A., Turgeon, M., Simon, A., Ho, E., \& Coombe, L. (2009). Nine year longitudinal retrospective study of taekwondo injuries. The Journal of the Canadian Chiropractic Association, 53(4), 272-281.

Kazemi, M., Alima, R., Ciantis, D. M. (2011). Weight cycling in adolescent taekwondo athletes. The Journal of the Canadian Chiropractic Association, 55(4), 318-324.

Khan, A., \& Joshi, M. (2011). Effect of taekwondo training on flexibility explosive power and strength of school going boys of Yavatmal city. International Referred Research Journal, 3(31), 55-56.

Kurian, M., Verdi, M. P., Caterino, L. C., \& Kulhavy, R. W. (1994). Relating scales on the children's personality questionnaire to training time and belt rank in ATA taekwondo. Perceptual and Motor Skills, 79(2), 904-906

Lakes, K. D., \& Hoyt, W. T. (2004). Promoting self-regulation through school-based martial arts training. Journal of Applied Developmental Psychology, 25(3), 283-302. doi:10.1016/j.appdev.2004.04.002

Landa, J. (2004). Risk and injuries in contact fighting. Journal of Combative Sport. Retrieved from http://ejmas.com/jcs/2004jcs/jcsart landa 0804.htm

Lantz, J. (2002). Family development and the martial arts: A phenomenological study. Contemporary Family Therapy 24(4), 565-580.

Levine, D. N. (2002). The masculinity ethic and the spirit of warriorhood in Ethiopian and Japanese cultures (chapter six). Revised version of paper presented at the World Congress of Sociology, Brisbane, Australia, July 8, 2002. Research Committee on Armed Forces and Conflict Resolution, Session 4: The Military and Masculinity. 
Lewis, P. (1996). The martial arts. London: Prion Books.

Lotfian, S., Ziaee, V., Amini, H., \& Mansournia, M. (2011). An analysis of anger in adolescent girls who practice the martial arts. International Journal of Pediatrics, 2011, 1-5. doi:10.1155/2011/630604

Movahedi, A., Bahrami, F., Marandi, S. M., Abedi , A. (2013). Improvement in social dysfunction of children with autism spectrum disorder following long term Kata techniques training. Research in Autism Spectrum Disorders, 7(9), 1054-1061. doi:10.1016/j.rasd.2013.04.012

Nosanchuk, T. A., \& MacNeil, M. L. (1989). Examination of the effects of traditional and modern martial arts training on aggressiveness. Aggressive Behavior, 15(2), 153-159.

Park, Y. H., Park, Y. H., \& Gerrard, J. (2009). Tae kwon do: The ultimate reference guide to the world's most popular martial art (3rd ed.). New York: Facts On File.

Pieter, W. (2005). Martial arts injuries. In D. J. Caine \& N. Maffulli (Eds.). Epidemiology of Pediatric Sports Injuries. Individual Sports. Medicine and Sport Science (pp. 59-73). Basel: Karger.

Pieter, W. (2009). Taekwondo. In In R. Kordi, N. Maffulli, R R. Wroble, \& W. A. Wallace (Eds). Combat sports medicine (pp. 263-286). London: Springer.

Steyn, B., \& Roux, S. (2009). Aggression and psychological wellbeing of adolescent taekwondo participants in comparison with hockey participants and non-sport group. African Journal for Physical, Health Education, Recreation and Dance, 15(1), 32- 43.

Tadesse, M. (2015). The role of taekwondo training on the subjective wellbeing of adolescents in Addis Ababa, Ethiopia. Revista de Artes Marciales Asiáticas, 10(2), 72-87. doi: 10.18002/rama.v10i2.1758

Tausk, G. P. (2001). Taekwondo. In T. A. Green (Ed). Martial arts of the world: an encyclopedia (pp. 608-617). California: ABC-CLIO.

Trulson, M. E. (1986). Martial Arts Training: A Novel "Cure" for Juvenile Delinquency. Human Relations, 39(12), 1131-1140. doi: 10.1177/001872678603901204

UN-HABITAT. (2008). Ethiopia: Addis Ababa Urban Profile. Nairobi: UNON.

United Nations Statistics Division. (2015). World Statistics Pocketbook (Series V, No. 39). New York: United Nations.

Vertonghen, J., \& Theeboom, M. (2010). The social-psychological outcomes of martial arts practice among youth: A review. Journal of Sports Science and Medicine, 9, 528-537.

Wargo, M., Spirrison, C., Thorne, M. \& Henley, T. (2007) Personality characteristics of martial artists. Social Behavior and Personality, 35(3), 399-408.

White, S. (2008). But what is wellbeing? A framework for analysis in Social and development Policy and Practice. WeD Working Paper 43. Retrieved from http://staff.bath.ac.uk/ecsscw/But what is Wellbeing.pdf

WTF. (n.d.). What is taekwondo? Retrieved from http://www.worldtaekwondofederation.net/

Zetaruk, M. N., Violán, M. A., Zurakowski, D., \& Micheli, L. J. (2005). Injuries in martial arts: a comparison of five styles. British Journal of Sports Medicine, 39(1), 29-33. doi: 10.1136/bjsm.2003.010322

Zivin, G., Hassan, N. R., DePaula, G. F., Monti, D. A., Harlan, C., Hossain, K. D., Patterson, K. (2001). An effective approach to violence prevention: Traditional martial arts in middle school adolescence. Adolescence, 36(143), 443-459.

\section{Author's biographical data}

Michael Emru Tadesse (Ethiopia), Master of Social Work, is a lecturer and head of the Department of Social Work at Mizan - Tepi University. His work has emphasized on examining the subjective wellbeing of University teachers and the contribution of martial arts to the wellbeing of adolescents. Michael has more than five years of experience in two different forms of martial arts, i.e., Taekwondo and Kung Fu. E-mail: michael.emru7@gmail.com. 